\title{
O intérprete universitário da Língua Brasileira de Sinais na CIDADE DE CURITIBA
}

\author{
A SIGN LANGUAGE UNIVERSITY LEVEL INTERPRETER WORKING IN THE CITY OF \\ CURITIBA
Ana Cristina GUARINELLO 1
Ana Paula SANTANA ${ }^{2}$
Luciana Cabral FIGUEIREDO 3
Giselle MASSI 4

RESUM O: no Brasil, o trabalho com intérpretes em Língua Brasileira de Sinais iniciou-se nos anos 80 e pode, dessa forma, ser considerado recente, assim como também é recente a legitimidade da sua importância que ainda está em processo de consolidação. A presente pesquisa tem como principal objetivo discutir e explicitar questões relativas ao trabalho de intérpretes de língua de sinais em uma universidade e dois centros universitários particulares da cidade de Curitiba. Para isto foram aplicados dois questionários para dois grupos distintos, um voltado para os intérpretes que atuam em universidades da cidade de Curitiba, e outro voltado para os surdos universitários que possuem intérpretes em sala de aula. Ambos os questionários continham questões abertas e fechadas. De acordo com as análises dos dados, constatou-se a importância dos intérpretes em sala de aula para o processo de aprendizagem dos estudantes surdos. Contudo, verificou-se também uma série de questões que subjaze a discussão sobre a efetividade no contexto da interpretação, tais como: qualidade na formação dos intérpretes, conhecimento antecipado da disciplina para a tradução, dificuldade na relação Língua Portuguesa/ LIBRAS, relação intérprete/ professor, dentre outras. A partir dessas considerações, vemos que, no cenário da educação dos surdos brasileiros, essas questões apenas refletem o descaso das autoridades com relação à educação dessa população, assim como evidenciam as dificuldades lingüísticas e sociais relativas à surdez. Esse trabalho apresenta-se, nessa direção, como o início de uma reflexão sobre o contexto do intérprete universitário, porém, muito ainda precisa ser entendido para que mudanças mais efetivas possam ser realizadas.

PALAVRAS-CHAVE: intérprete para surdos; surdez; língua brasileira de sinais; educação especial.

A BSTRACT: in Brazil, work with Brazilian sign language (Libras) interpreters began in the eighties, so this can be said to be a recent proposal, as is recent the consideration of sign language as a legitimate and important language, which is an ongoing process. The main objective of this study is to discuss some issues concerning the context of sign language interpreters within one private university and two community college centers in the city of Curitiba. Two questionnaires were applied with two distinct groups: one with the interpreters that work in university and colleges in Curitiba, and another with the deaf university students who have interpreters in their classes. Both questionnaires had open and closed questions. The data analyses showed that the interpreters were important to the deaf students' learning processes. Nevertheless, the results also highlighted a number of issues underlying the discussion about effectiveness of interpretation in the university context i.e.: the quality of the interpreter preparedness, previous understanding or preparation of the subject matter content, difficulties in the relation to Portuguese/ Libras, difficulties in the relationships between interpreter and teacher, among others. From these considerations, it is clear that the Brazilian scene for education of deaf people reflects the lack of involvement of public authorities as to deaf education. There are still a great many linguistic and social challenges related to deaf education at theuniversity level. This study intends to present an initial discussion about interpreters at the university level, nevertheless, much still has to be understood in order for effective changes to occur.

KEYWO RD S: sign language interpreter; deafness; Brazilian sign language; special education.

\footnotetext{
$1_{1}$ Doutora em Estudos Lingüísticos pela UFPR, docentedo Curso de Graduação em Fonoaudiologia edo Mestrado e Doutorado em Distúrbios da Comunicação da Universidade Tuiuti do Paraná. - ana.guarinello@utp.br

2 Doutora em Lingüística pela UN ICAMP, docente do Curso de Graduação em Fonoaudiologia e do M estrado e Doutorado em Distúrbios da Comunicação da Universidade Tuiuti do Paraná. - ana.santana2@utp.br

3 Mestranda em Distúrbios da Comunicação pela UTP - Iucianaaf@hotmail.com

4 Doutora em Estudos Lingüísticos pela UFPR, docente do Curso de Graduação em Fonoaudiologia e do Mestrado e Doutorado em Distúrbios da Comunicação da Universidade Tuiuti do Paraná. - giselle.massi @utp.br.
} 


\section{INTRODUÇÃO}

O trabalho do intérprete em Língua Brasileira de Sinais (LIBRAS) é recentee a legitimidade da sua importância ainda está em processo deconsolidação, uma vez que o reconhecimento da LIBRAS 5 enquanto língua dos surdos ocorreu há apenas cinco anos. Com a sua oficialização, em abril de 2002 (BRASIL, 2002), houve um avanço na direção da inclusão dos surdos no ensino regular. A pesar disso, essa inclusão ainda não é satisfatória, já que as pessoas com necessidades especiais necessitam de uma série de condições que, na maioria das vezes, não têm sido propiciadas pela escola (LACERDA, 2006), dentre elas, a presença de um intérprete na sala de aula.

De início, convém comentar que a oficialização da LIBRAS ocasionou implicações de diversos aspectos: social - o surdo tem direito a intérpretes em contextos públicos; subjetivo - o surdo necessita de uma língua para se constituir enquanto sujeito; cognitivo - o surdo precisa de uma língua para pensar; terapêutico - a utilização da abordagem bilíngüe no contexto clínico; e educacional - o surdo necessita que os conteúdos escolares sejam interpretados a partir da LIBRAS por um intérprete.

A história da constituição do intérprete de língua de sinais iniciou-se por meio de atividades voluntárias que foram valorizadas na medida em que os surdos passaram a desenvolver o exercício da cidadania e em paralelo com a proposta de educação bilíngüe (QUADROS, 2004). No Brasil, o trabal ho com intérpretes iniciou-se nos anos 1980, principalmente, em função de serviços religiosos e informais. N esse contexto, a FENEIS ${ }^{6}$ passou a organizar encontros de intérpretes de LIBRAS.

As discussões sobre o intérprete enquanto profissional, segundo Famularo (1999), são relativamente recentes. Conforme a autora, no Congresso da Federação Mundial de Surdos, realizado na Finlândia em 1987, houve a recomendação para que a formação de intérpretes de língua de sinais contasse com as mesmas exigências daquelas vinculadas aos intérpretes das línguas estrangei ras orais. Já em 1995, em congresso realizado pela mesma Federação, na Áustria, foi estabel ecida uma Comissão de Interpretação, o que demonstrou um avanço nas discussões da comunidade surda mundial.

\footnotetext{
${ }^{5}$ Cabe esclarecer que a oficialização da LIBRAS ocorreu durante a década de 1990 inicialmente em alguns municípios e estados brasileiros. Porém, apenas em 2002, a partir da a Lei Federal n 10.436, é que a língua de sinais foi legalizada em todo território nacional. Essa Lei também dispõe que os sistemas educacionais federal, estadual e municipal devem garantir a inclusão da LIBRAS nos cursos de educação especial, de fonoaudiologia e de magistério, nos níveis médio e superior, como parte integrante dos Parâmetros Curriculares Nacionais.

${ }^{6}$ A criação, em 1987, da Federação N acional de Educação e Integração dos Surdos (FENEIS), sob a direção de surdos, contribuiu para o reconhecimento da LIBRAS e, conseqüentemente, para o fortal ecimento da luta pelos direitos dos surdos. Vinculada à $W$ orld F ederation of the $D$ eaf, a mesma tem o objetivo de garantir os direitos culturais, sociais e lingüísticos dessa comunidade. Visando a promoção da língua de sinais, a FENEIS criou cento e quarenta associações de surdos no Brasil. Além disso, é responsável pela certificação e fiscalização de intérpretes de língua de sinais.
} 
No Brasil, em 22 de dezembro de 2005, criou-se o Decreto $n^{\circ} 5.626$ que considera como tradutor e intérprete da língua de sinais e da língua portuguesa aquele que interpreta de uma língua fonte para outra língua alvo. Segundo tal decreto, a formação desse intérprete deve efetivar-se por meio de curso superior deTradução el nterpretação, com habilitação em LIBRAS/ língua portuguesa. Essa formação permite que o intérprete da LIBRAS atue na educação infantil, na educação fundamental e na universidade.

No entanto, convém ressaltar que, no Brasil, o intérprete encontra possi bilidades restritas para o seu exercício profissional, com baixa remuneração e difícil acesso a cursos referentes à sua área de atuação, os quais são geralmente ofertados nos grandes centros urbanos (PIRES; NOBRE, 2000). Por essas razões, ainda é escasso o número de pessoas habilitadas para cumprir essa função. Desta forma, os contextos educacionais que efetivamente contam com a prática de intérpretes em sala de aula são limitados, principalmente, no ensino fundamental e universitário (PIRES; NOBRE, 2000).

Desdeo início do século XX, os surdos quefreqüentavama escola regular apresentavam, de forma geral, dificuldades na aquisição da língua portuguesa. Contudo, naquela época, eram mais escassas as medidas específicas de apoio à educação da comunidade surda. Os surdos que se matriculavam no ensino regular tinham que se adaptar aos mesmos modelos pedagógicos usados na educação dos ouvintes. Entretanto, tais modelos não atendiam as necessidades próprias de educação do surdo, gerando dificuldades no processo de escolarização dessa população. Como resultado, um número significativo desurdos, apesar depassarem por anos de escolarização, apresentavam várias dificuldades com relação ao seu desempenho acadêmico, quando comparados com ouvintes (GUARINELLO, 2007).

A tual mente, a política de educação no Brasil tem o objetivo de viabilizar uma educação integradora, ou seja, uma educação organizada de forma a atender a todos, incluindo os portadores denecessi dades especiais dentro da escola regular (A LEN CAR, 1994). Essa política encontra-se explicitada em propostas curriculares, nas quais o Ministério da Educação propõequeas escolas regulares devem oferecer, em sua organização, atividades em dassecomum eserviços deapoio especial izados para os surdos (BRASIL, 2002).

A inserção do intérpretena sala de aula podeser entendida como uma maneira deminimizar as dificuldades dos surdos, já que, em geral, esses encontram uma desigualdade lingüística dentro da sala de aula, por não ter uma língua compartilhada com seus colegas e professores ouvintes. Segundo Lacerda (2002), ainda são poucas as escolas atentas a essa problemática, ou seja, poucas são as escolas que têm permitido ou proposto a inserção do intérprete em sala de aula como possibilidade para solucionar, ou minimizar, problemas lingüísticos enfrentados pela comunidade surda no cotidiano escolar.

Lacerda (2000) realizou um estudo com o objetivo de investigar a dinâmica e peculiaridades das relações pedagógicas estabelecidas em uma sal a de 
aula, na qual foi inserida uma criança surda e uma intérprete. Por meio da análise da organização do trabal ho pedagógico nesta sala de aula, a autora concluiu quea inclusão desejada e descrita na lei não é efetivamente alcançada, mesmo com a presença do intérprete. Para a autora há a necessidade da real ização de um projeto educacional amplo, que assuma a surdez com suas características próprias, por meio de revisões das estratégi as pedagógicas, da organização do espaço acadêmico e de um currículo que contemple as necessidades da comunidade surda.

Quando se insere um intérprete da LIBRAS em uma sala de aula abre se a possibilidade do aluno surdo receber a informação escolar nessa língua, por meio de uma pessoa competente. Ao mesmo tempo, o professor ouvinte pode ministrar suas aulas sem se preocupar em como passar a informação em sinais, atuando em sua língua de domínio. Pode-se afirmar que, nesse caso, a condição lingüística especial do surdo érespeitada, o que aumenta a chancedeledesenvolverse e construir novos conhecimentos satisfatoriamente (LACERDA, 2000).

Kelman (2005) ressalta a importância do intérprete para o aluno surdo em uma sala de aula regular. Essa autora realizou um estudo com o objetivo de descrever os papéis queo intérpreteassumeem contextos educacionais inclusivos. Para isso, aplicou questionários junto a esses profissionais. N esse estudo, a autora afirma que os intérpretes assumem onze diferentes papéis dentro da sala de aula. O primeiro deleséo de ensinar ao surdo a língua portuguesa como segunda língua. Também foi citado como papel do intérprete, dentro da sala de aula, o ensino da própria língua de sinais aos surdos e ouvintes, a fim de facilitar a comunicação destes com os alunos surdos. O intérprete também é responsável pela adequação curricular, que acontece em forma de omissão de alguns conteúdos, pois alguns professores relatam que os al unos ouvintes ficam inquietos ao precisarem esperar pelos al unos surdos. Outro papel exercido pelo intérprete que atua em sala de aula é participar do planejamento das aulas e integração junto com o professor, para que o conteúdo seja ministrado da melhor forma possível para os surdos. Em relação aos alunos surdos, o intérprete deve orientá-lo, explicando detalhadamente os exercícios e conteúdos trabal hados, assegurando-se de que houve entendimento por parte do aluno.

No entanto, o intérprete também deve promover a autonomia deste aluno. O intérprete tem também o papel de orientar e interpretar a comunicação entre colegas surdos e ouvintes e de utilizar a comunicação multimodal, ou seja, usar diversos canais de comunicação para garantir a compreensão designificados. Por último, el etambém deve promover a tutoria, orientando o surdo na organização desuas atividades acadêmicas. Kelman (2005) também enfatizou queas diferentes atuações do intérprete possi bilitam discussões pedagógicas entre o intérprete e o professor, ressaltando que este pode ser um argumento promotor da inclusão.

Várias dúvidas referentes aos papéis do intérpretevêm sendo discutidas por diversos pesquisadores. Segundo Rosa (2003), primeiramente, o intérpretedeve inteirar-se do conteúdo a ser interpretado. Pois, se o intérprete não domina a língua 
de sinais ou a língua portuguesa, comprometerá o seu trabalho de interpretação. Além disso, qualquer interpretação exigetambém queo intérpreteseja conhecedor do assunto tratado em sala de aula.

Segundo Famularo (1999), a interpretação não é tarefa fácil, uma vez quenão envolvemeramente um ato mecânico de substituir palavras deuma língua para outra. O intérpretedeveconhecer com profundidadetanto a língua portuguesa quanto a LIBRA S para que compreenda as intenções de quem fal a, encontrando os termos equival entes possíveis. Para a autora, a interpretação é um processo que envolve a necessidade tomar decisões sintáticas, semânticas e pragmáticas.

Entretanto, a interpretação não podeser vista apenas como uma tomada de deci sões sobre a organização dos níveis lingüísticos. Nesse sentido, é relevante entender o contexto da formação do intérprete e de suas dificuldades na prática educacional. Essa formação deve envolver discussões sobre concepção de linguagem, de língua, de tradução, de interpretação. A interpretação não é uma decodificação, como se o sentido estivesse na língua. A partir do momento em que consideramos que um discurso é um efeito de sentido entre os interlocutores, conforme Pêcheux (1990), evidenciamos o quanto do intérprete está presente na interpretação. Ou seja, entre uma língua e outra há um sujeito que atribui sentidos em uma língua etenta constituir sentidos em outra. Entende-se, nessa visão, quea linearidade da linguagem é uma ilusão.

É fato amplamenteconhecido quemuitos intérpretes não têm domínio do assunto quevão interpretar, gerando a supressão, adição ou confusão deinformações, o que faz com que o surdo, constantemente, mesmo contando com a ajuda de um intérprete, não tenha acesso a mesma informação que os seus pares ouvintes.

Dessa forma, vale salientar que a colocação do intérprete em sala de aula não si gnifica que a questão de educação dos surdos está resolvida. Já que nem todos os surdos conhecem eutilizam a língua desinais, o quefaz com queo trabalho do intérpreteseja direcionado apenas aos surdos usuários desta língua. Além disso, a presença do intérpretenão assegura que questões metodológi cas particulares de cada escola sejam consideradas, ou ainda que o currículo aborde peculiaridades e aspectos culturais da comunidade surda.

Tendo em vista que a universidade, enquanto agência de formação, é capaz de produzir conhecimento e de qualificar os recursos humanos envolvidos, esse artigo pretende discutir eexplicitar questões relativas ao trabal ho deintérpretes delíngua desinais em uma universidadee dois centros universitários particulares da cidade de Curitiba.

\section{Método}

Para a realização dessa pesquisa, foram aplicados dois questionários queversavam sobreo ensino/ aprendizagem perpassados por uma segunda língua, no caso, a LIBRAS. Um questionário foi entregue ao Grupo 1, composto por sete intérpretes de língua de sinais/ língua portuguesa que atuavam em uma 
universi dade e em dois centros universitários particulares da cidade de Curitiba. O segundo foi entregueao Grupo 2, composto por seis al unos surdos universitários que estudavam em distintas universi dades e centros universitários particulares de Curitiba e que possuíam intérpretes em sala de aula. Cabe esclarecer que cada aluno surdo freqüentava cursos universitários diferentes. A mbos os grupos responderam aos questionários individualmente e por escrito. Durante o preenchimento das respostas não houve interferência dos pesquisadores.

A ntes da aplicação dos questionários, os pesquisadores explicaram para os intérpretes e os alunos surdos os objetivos da pesquisa e solicitaram, aos que aceitaram participar da mesma, que assinassem o termo de consentimento livree esclarecido.

As respostas foram anal isadas qual itativamente e quantitativamente. Para tanto, foram elencados os conteúdos que apareceram com maior recorrência nas respostas fornecidas pel os sujeitos da pesquisa e estabel eci da uma organização por temáticas. Ressaltamos que essa pesquisa foi aprovada pelo Comitê de Ética da Universidade Tuiuti do Paraná, conforme o protocolo 076/ 2006.

\section{Resultados e discussão}

$\mathrm{Na}$ tabela 1, constam dados pessoais dos intérpretes com relação à idade, formação e órgão competente para obtenção do título de intérprete.

Tabela 1- Dados pessoais dos intérpretes.

\begin{tabular}{|c|c|c|c|}
\hline Intérpretes & Idade & Formação & Órgão competente \\
\hline Intérprete 1 & 38 & $\begin{array}{l}\text { Pedagogia com Pós-Graduação em } \\
\text { Psicopedagogia. Mestrado em } \\
\text { Educação }\end{array}$ & $\begin{array}{l}\text { Feneis e Secretaria de Educação do } \\
\text { Paraná }\end{array}$ \\
\hline Intérprete 2 & 24 & $\begin{array}{l}\text { Pedagogia. Pós-Graduação em } \\
\text { Educação Especial }\end{array}$ & $\begin{array}{l}\text { Feneis e Secretaria de Educação do } \\
\text { Paraná }\end{array}$ \\
\hline Intérprete 3 & 41 & $\begin{array}{l}\text { Teologia. Pós-Graduação em } \\
\text { Educação FENEIS }\end{array}$ & $\begin{array}{l}\text { Feneis e Secretaria de Educação do } \\
\text { Paraná }\end{array}$ \\
\hline Intérprete 4 & 34 & $\begin{array}{l}\text { Pedagogia. Pós-Graduação em } \\
\text { Psicopedagogia, Psicomotricidade }\end{array}$ & Feneis \\
\hline Intérprete 5 & 26 & Nível Médio & $\begin{array}{l}\text { Feneis e Secretaria de Educação do } \\
\text { Paraná }\end{array}$ \\
\hline Intérprete 6 & Não respondeu & $\begin{array}{l}\text { Letras. Pós-Graduação em } \\
\text { Educação Especial }\end{array}$ & $\begin{array}{l}\text { Feneis e Secretaria de Educação do } \\
\text { Paraná }\end{array}$ \\
\hline Intérprete 7 & 33 & $\begin{array}{l}\text { Educação Artística. Artes Cênicas. } \\
\text { Pós-Graduação em Educação } \\
\text { Infantil }\end{array}$ & Secretaria de Educação do Paraná \\
\hline
\end{tabular}

A média de idade dos sete intérpretes entrevistados é de 32,6 anos. Com relação à escolaridade, seis intérpretes, ou seja, 86,71\% possuíam pósgraduação eapenas um possuía ensino médio. Todos os intérpretes possuíam título de intérprete, sendo que 86,71\% receberam o título da Secretaria de Educação vinculada a FEN EIS, eapenas um intérpreteconseguiu o título somentevia FENEIS. 
$\mathrm{Na}$ tabela 2 são explicitadas as respostas relativas às atividades de interpretação.

Tabela 2 - Atividades de interpretação.

\begin{tabular}{|c|c|c|c|}
\hline Intérpretes & $\begin{array}{l}\text { Aptidão para } \\
\text { interpretar }\end{array}$ & Dificuldades para interpretar & O que poderia melhorar \\
\hline Intérprete 1 & $\begin{array}{l}\text { Curso de LIBRAS, } \\
\text { contato com surdos }\end{array}$ & $\begin{array}{l}\text { Deveríamos ter área específica no } \\
\text { momento de atuação em sala de } \\
\text { aula }\end{array}$ & $\begin{array}{l}\text { Todos os intérpretes deveriam ter } \\
\text { conhecimento prévio do conteúdo. } \\
\text { Ter associação de Intérpretes }\end{array}$ \\
\hline Intérprete 2 & $\begin{array}{l}\text { Curso de LIBRAS, } \\
\text { contato com surdos }\end{array}$ & Depende da área & Áreas específicas para interpretar. \\
\hline Intérprete 3 & $\begin{array}{l}\text { Contato com } \\
\text { surdos }\end{array}$ & Não tem dificuldades & Não respondeu. \\
\hline Intérprete 4 & $\begin{array}{l}\text { Contato com } \\
\text { surdos }\end{array}$ & Não tem dificuldades & Aprimoramento na língua de sinais. \\
\hline Intérprete 5 & $\begin{array}{l}\text { Contato com } \\
\text { surdos }\end{array}$ & Não tem dificuldades & Não respondeu \\
\hline Intérprete 6 & $\begin{array}{l}\text { Contato com } \\
\text { surdos }\end{array}$ & Não tem dificuldades & Não respondeu \\
\hline Intérprete 7 & $\begin{array}{l}\text { Curso de LIBRAS, } \\
\text { contato com } \\
\text { surdos. }\end{array}$ & $\begin{array}{l}\text { A língua de sinais não é uma só, } \\
\text { então interpretando para várias } \\
\text { clientelas acabo usando } \\
\text { diferentes sinais para a mesma } \\
\text { coisa. Cansaço por interpretar } \\
\text { muitas horas por dia. }\end{array}$ & $\begin{array}{l}\text { Aprimoramento constante na língua } \\
\text { de sinais. }\end{array}$ \\
\hline
\end{tabular}

Com relação à aptidão para interpretar, todos os intérpretes (100\%) citaram o contato com surdos e três intérpretes (42,8\%) também citaram curso de LIBRA S como viabilidadepara o exercício da profissão. Esses dados parecem sugerir que, nesse momento histórico, a experiência pessoal é significativa na área da interpretação. A análise dos dados evidencia que, embora o Decreto $n^{\circ}$ 5.626/ 05 considere importante o curso superior de Tradução el nterpretação com habilitação em LIBRAS/ língua portuguesa para a formação do intérprete da língua de sinais e da língua portuguesa, apenas um dos intérpretes dessa pesquisa tinha formação em Letras. Todos os demais parecem ter se constituído como intérpretes a partir depráticas pessoais que incluem o contato com sujeitos surdos em igrejas, na própria família e em escolas especiais.

Os dados indicam que, para os sujeitos dessa pesquisa, a experiência pessoal émais significativa do queum diploma acadêmico na área deinterpretação. Isso é, possivel mente, resultado da própria história da constituição dos intérpretes na área da surdez que se iniciou por meio de atividades voluntárias e informais. Além disso, existem poucos cursos superiores no Brasil que têm habilitação em LIBRAS/ língua portuguesa.

Quanto às dificuldades encontradas no momento da interpretação, quatro intérpretes $(57,1 \%)$ afirmaram não possuir dificuldades, embora um deles refira necessitar de aprimoramento em LIBRAS, evidenciando, assi m, um discurso contraditório. Três (42,8\%) responderam que tinham dificuldades. Um (14,2\%) intérprete afirmou que possuía dificuldades, pois não tinha um local específico 
para atuar em sala de aula, fato que dificultava seu trabal ho, sendo sugerida uma área específica para interpretação dentro da sala de aula. Outro intérprete (14,2\%) referiu quetinha dificuldades em conteúdos específicos, pela fal ta deconhecimentos do assunto tratado em sala de aula. E outro $(14,2 \%)$ ainda informou que tinha dificuldades, já que interpretava para vários surdos deáreas diferentes eque, muitas vezes, apresentava cansaço devido a muitas horas de trabalho.

Duas questões chamam atenção nesses resultados com relação às dificuldades dos intérpretes. Primeiramente, o local na sal a de aula queo intérprete deve posicionar-se aparece como relevante no contexto da interpretação na área da surdez, diferente do intérprete das línguas orais. O surdo precisa ter uma excel entevisibilidade do intérpreteque deveestar em um lugar com boa iluminação e em frente ao aluno. Contudo, não pode ocupar um espaço que atrapalhe a aula do professor ea visualização do quadro negro.

Com relação à pergunta sobre o que poderia ser feito para mel horar o trabal ho deinterpretação, três intérpretes (42,8\%) não responderam à questão. Dois intérpretes (28,5\%) citaram aprimoramento constante da LIBRAS. Esseaspecto foi ressal tado tal vez pelo fato deo intérpretesentir necessidade de uma relação direta entre o sinal na língua de sinais e a palavra na língua portuguesa. Contudo, essa rel ação entreas línguas não é direta nem necessária. Os léxicos de uma língua não precisam, necessariamente, coincidir com os da língua interpretada, já queas línguas têm estruturas particulares e, nesse caso, uma palavra não precisa ter uma correspondente em outra. Como exemplo disso, é possível citar, no contexto da língua portuguesa, a expressão "saudade”, a qual não conta com um correspondente direto na língua inglesa.

Caberessaltar, ainda, quea língua desinais como qual quer outra língua está em constantemovimento etransformação, denotando a relação entreas práticas sociais e a língua. É por isso que, a partir do momento em que as práticas sociais dos surdos vão mudando, novos léxicos vão sendo acrescentados a língua desinais. O mesmo acontece também na nossa língua portuguesa quando, por exemplo, com o desenvol vimento da informática, passamos a nomear novos instrumentose ações realizadas com esses instrumentos como: escanear, del etar, entre outros.

N o caso da interpretação, no contexto das disciplinas universitárias, o que ocorreéqueo intérprete defronta-se justamente com uma situação em que aparecem léxicos na língua portuguesa que são relativamente novos nas práticas com a língua desinais e, nessecaso, pela falta do léxico, o intérprete usa o al fabeto manual, fazendo apenas uma transposição para a língua portuguesa. Fato que pode deixar o surdo incapaz de compreender o assunto que está sendo trabal hado em sala de aula.

Nessa mesma questão, um intérprete $(14,2 \%)$ respondeu que deveria ter conhecimento prévio dos conteúdos interpretados, uma vez que, a falta de conhecimento antecipado acerca da disciplina que vai interpretar, dificulta a interpretação, poiséimpossível para o intérpreteconhecer todos os conteúdos das diferentes áreas do conhecimento. 
Ainda com relação ao que poderia ser feito para melhorar seu trabalho, um intérprete $(14,2 \%)$ respondeu que deveria escolher as disciplinas e cursos que pode interpretar a depender de seu conhecimento sobre o tema.

Quando questionados sobre o grau de satisfação com a atividade de interpretação, todos os intérpretes responderam estarem satisfeitos.

Com relação ao questionário aplicado com surdos adultos universitários, na Tabela 3, apresentamos parte dos resultados referentes às seguintes questões: curso de graduação, percepção de mudança após o momento em que passaram a assistir aulas com intérpretes, quantidade de disciplinas que tem intérpretes e critérios para escolha de cada disciplina.

Tabela 3 - A preciação do papel do interprete por surdos.

\begin{tabular}{|c|c|c|c|c|}
\hline Sujeitos & Curso & $\begin{array}{l}\text { O que mudou quando } \\
\text { começou a assistir aulas com } \\
\text { intérpretes }\end{array}$ & $\begin{array}{l}\text { Quantidade de } \\
\text { disciplinas que } \\
\text { tem intérpretes }\end{array}$ & Quais os critérios de escolha \\
\hline Sujeito 1 & Administração & $\begin{array}{l}\text { O aprendizado foi melhor, } \\
\text { aprendi e tive mais } \\
\text { informações }\end{array}$ & 4 & $\begin{array}{l}\text { Grau de dificuldade da } \\
\text { disciplina } \\
\text { Professor que só fala e não } \\
\text { utiliza o quadro }\end{array}$ \\
\hline Sujeito 2 & Pedagogia & Não respondeu & Não respondeu & Disciplina teórica \\
\hline Sujeito 3 & Pedagogia & $\begin{array}{l}\text { Eu aprendi muitas coisas e } \\
\text { também mais informações }\end{array}$ & 4 & $\begin{array}{l}\text { Grau de dificuldade da } \\
\text { disciplina }\end{array}$ \\
\hline Sujeito 4 & Design Gráfico & $\begin{array}{l}\text { Notas mais altas, mais } \\
\text { conhecimentos, mais } \\
\text { segurança }\end{array}$ & 3 & Disciplina teórica \\
\hline Sujeito 5 & Pedagogia & Melhor compreensão & 3 & Disciplina teórica \\
\hline Sujeito 6 & Não respondeu & Melhor compreensão & Não respondeu & $\begin{array}{l}\text { Grau de dificuldade da } \\
\text { disciplina }\end{array}$ \\
\hline
\end{tabular}

Na tabela 3 é possível verificar que três surdos (50\%) estão cursando pedagogia, um (16,67\%) cursa administração, um (16,67\%) cursa Design Gráfico e um $(16,67 \%)$ sujeito não respondeu a questão. Com rel ação às mudanças ocorridas após a presença de um intérprete em sala de aula, um sujeito $(16,67 \%)$ não respondeu a questão, os outros cinco (83,3\%) citaram que passaram a compreender melhor o conteúdo, sendo que dentre os cinco, um sujeito referiu que se sentemais seguro e outro que suas notas melhoraram.

Nesses resultados, chama atenção o fato de que apesar dos intérpretes referirem quena maioria das vezes não possuem conhecimento prévio das disciplinas, o que prejudica, evidentemente, a interpretação, para os sujeitos surdos a presença desses profissionais é fundamental para sua aprendizagem. N esse ponto, convém questionar o quanto essa interpretação ganharia em qualidade se os intérpretes tivessem acesso prévio ao conteúdo. Ressaltamos, a partir da análise das respostas dadas pelos sujeitos surdos, que, apesar das dificuldades dos intérpretes, há um aumento considerável da inteligibilidade do conteúdo pelo surdo.

Com relação à quantidade de disciplinas que podem dispor de um intérprete, dois sujeitos (33,3\%) não responderam à questão, dois $(33,3 \%)$ 
responderam que contam com intérprete em três disciplinas e dois $(33,3 \%)$ em quatro disciplinas. Os critérios para escolha das disciplinas, segundo três sujeitos (50\%), dependem do grau de dificuldade da disciplina. Outros três (50\%) salientaram o fato de a disciplina ser teórica como fator determinante para se ter auxílio do intérprete em sal a de aula.

Percebemos que os surdos, sujeitos dessa pesquisa, não têm, ainda, a possibilidade de contar com um intérprete em todas as situações do contexto educacional. A lém disso, eles afirmam que precisam escolher dentre as disciplinas mais difíceis ou mais teóricas para eles. Mas essas disciplinas não seriam, também, mais difíceis para os intérpretes? Já que a questão é o conteúdo? Os surdos entrevistados nessa pesquisa revelaram que a escolha das disciplinas que tem intérprete é feita, geralmente, na primeira semana de aula. Primeiramente, eles assistem as aulas sem intérpretee, em um segundo momento, devem escolher três ou quatro disciplinas consideradas mais difíceis para solicitar a presença do intérprete.

Portanto, esses sujeitos não contam com uma situação ideal dentro da sal a de aula, uma vez que eles podem escolher apenas três ou quatro disciplinas a serem traduzidas. N esse caso, é possível afirmar que, embora instrumentos legais anunciem quea LIBRAS deve estar presentedurantetoda a permanência dos surdos na universidade, tais surdos ainda não logram desse benefício.

O grau de dificuldade, decidido na primeira semana de aula, também é algo difícil de ser analisado. O surdo pode equivocar-se nessa escolha, já que teve pouco contato com o professor e com a matéria. O problema ainda aumenta em al gumas situações nas quais o surdo é impossi bilitado de mudar sua escolha. Parte-se, assim, de uma idéia de que a aprendizagem de um conteúdo é uniforme, sempre fácil, sempre difícil e independente da metodologia do professor, do conhecimento do surdo sobre o assunto, do seu interesse em aprender e, é claro, do conteúdo a ser ministrado.

A pesar da universidade e dos centros universitários pesquisados oferecerem critérios deescol ha das disciplinas para os al unos surdos quenecessitam de intérprete, a situação ideal seria que os alunos pudessem dispor de intérpretes em todas as disciplinas independente do seu grau de dificuldade, conforme garantido pelo Decreto Federal $n^{\circ} 5626$ de 2005. Nas disciplinas que não contam com intérpretes, os surdos, em geral, fazem uso da leitura orofacial.

Entretanto, a leitura orofacial é bastante cansativa, já que, para compreender um assunto só por meio da leitura orofacial, os surdos precisariam passar a aula inteira ol hando para o professor sem nem sequer piscar ou virar-se para o lado, pois perderiam parte da informação. Além disso, outros fatores prejudicam a leitura orofacial, como por exemplo, a pouca iluminação de uma sala de aula, a má articulação de um professor, a distância entre o professor e o al uno, o desconhecimento determos eexpressões da língua portuguesa por partedeal guns surdos, o uso de bigodes grandes por alguns professores, entre outros fatores.

Quando questionados sobreo comportamento do professor em relação ao intérprete, três surdos (50\%) afirmaram que estes conversam ocasionalmente 
com os intérpretes sobre as disciplinas, um (16,67\%) afirmou que o professor age com indiferença à presença do intérprete em sua aula, um $(16,67)$ sugeriu outro tipo de comportamento por parte do professor, sendo que não especificou qual, e um (16,67\%) não respondeu a questão. Essa pesquisa evidencia que, em geral , não há uma troca entre os intérpretes e os docentes. Contudo, ressaltamos que o intérprete deveria dialogar sobre os conteúdos com o professor, revelando suas dúvidas, as questões do al uno e, por vezes, mediando a relação do professor com o aluno para que o conhecimento seja construído. Porém, como isso é possível em um ambiente em que, segundo os sujeitos dessa pesquisa, os professores e intérpretes conversam ocasi onal mente ou no qual o professor age com indiferença com relação ao intérprete?

Quanto ao grau de satisfação referente ao desempenho do intérprete, dois surdos (33,33\%) afirmaram estarem satisfeitos com seus intérpretes, outros dois (33,33\%) informaram estar muito satisfeitos, um (16,67\%) afirmou estar pouco satisfeito com o intérprete, justificando sua resposta devido a atrasos, confusão e preguiça por parte do profissional, e um (16,67\%) não respondeu a questão.

Com relação ao fato de contar com o trabal ho deum intérpreteem sala de aula ter causado al gum problema para o al uno, quatro surdos $(66,67 \%)$ afirmaram que não e dois (33,33\%) indicaram quesim, justificando suas resposta ao citarem queestes problemas estão relacionados à falta de atenção do intérprete durante o trabalho e com o fato de conversar com o intérprete sobre outros assuntos duranteas aulas.

\section{Conclusões}

Essa pesquisa procurou discutir eexplicitar questões rel ativas ao trabalho deintérpretes delíngua desinais em uma universidadeedois centros universitários particulares da cidadedeCuritiba. Há muito vem sendo discutido sobrea importância da presença do intérpretepara o aluno surdo. Contudo, apesar dehaver modificações nesse sentido por partedas universidades, as quais vêm trabalhando com intérpretes em al gumas situações, ainda não se chegou a um cenário ideal para o surdo. O que vemos é que há muitas questões a serem analisadas e modificadas, tais como o conhecimento prévio por parte dos intérpretes sobre o conteúdo das disciplinas a serem ministradas, o número dedisciplinas a serem interpretadas, assim como léxicos específicos de cada língua utilizados nesse contexto.

De seu lado, os surdos que participaram dessa pesquisa afirmam que são surpreendidos na primeira semana deaula ao ter quefazer uma escol ha acerca das disciplinas a serem interpretadas, sem estarem preparados para tal. E essa escolha, conformecitado por al guns, não permiteal terações posteriores. Além disso, a dificuldade com a compreensão da língua portuguesa faz com que os surdos supervalorizem os intérpretes fazendo poucas referências à qualidade da interpretação. Mas, com certeza, essa interpretação nem sempre é fidedigna ou mesmo de qualidade, pois os intérpretes comentaram sobre suas dificuldades no momento em que é realizada a tradução simultânea. 
Cabe esclarecer que mais importante do que as mudanças na atuação dos intérpretes é a presença deste profissional dentro das escolas, visto que na maioria das escolas brasileiras essa presença ainda não está garantida. N a política nacional atual alunos surdos, de maneira geral, são obrigados a estudar em escolas monolíngües, sem a presença de intérpretes e sem levar em consideração as diferenças lingüísticas do surdo.

A partir dessas considerações, vemos que, no cenário da educação dos surdos brasileiros, essas questões apenas refletem o descaso das autoridades com relação à educação dessa população, assim como evidenciam as dificuldades lingüísticas e sociais relativas à surdez. Esse trabal ho apresenta-se, nessa direção, como o início de uma reflexão sobre o contexto do intérpreteuniversitário, porém, muito ainda precisa ser entendido para que mudanças mais efetivas possam ser realizadas.

\section{REFERÊNCIAS}

ALENCAR, E.M.L.S. (Org.). Tendências atuais e desafios da educação especial. Brasília: MEC, 1994. (Série Atualidades Pedagógicas)

BRASIL. Ministério da Educação. Secretaria de Educação Especial. Ensino de Língua P ortuguesa para surdos: caminhos para a prática pedagógica. Brasília: MEC/ SEESP, 2002.

. Lei n 10436, de24 deabril de2002. Língua Brasileira deSinais - LIBRAS. Brasília, 2002.

FAMULARO, R. Intervención del interpretedesenas / lengua oral en el contrato pedagógico de la integración. In. SKLIAR, C. (Org.) A tualidades da educação bilíngüe para surdos. Porto Alegre: Mediação, 1999. v.1.

GUARINELLO, A.C. 0 papel do outro no contexto desujeitos surdos. São Paulo: Editora Plexus, 2007.

KELMAN, C. A. Os diferentes papéis do professor intérprete. Espaço: Informativo TécnicoCientífico, Rio deJaneiro, v. 24, p. 25-30, 2005.

LACERDA, C. B. F. A criança surda e a língua de sinais no contexto de uma sala de aula de alunos ouvintes. Relatório Final FA PESP Proc. № 98/ 02861-1, 2000.

O intérprete educacional de língua de sinais no Ensino Fundamental: refletindo sobre limites e possibilidades. In: LODI, A.C.B et al.. (Org.) Letramento e minorias. Porto Alegre: Mediação. 2002. p.120-128.

. A inclusão escolar de alunos surdos: o que dizem alunos, professores e intérpretes sobre esta experiência. Cad. Cedes, Campinas, v. 26, n.69, p. 163-184, 2006.

PÊCHEUX, M. Por uma análise automática do discurso. Campinas: Unicamp, 1990.

PIRES, C.L.; NOBRE, M. A. Interpretação em língua de sinais: um olhar de perto. Espaço: informativo técnico-científico, Rio de Janeiro, v. 14, p.12-18, 2000.

QUADROS, R. M. de. 0 tradutor-intérprete de língua brasileira de sinais e língua portuguesa. 2. ed. Brasília: MEC. 2004.

ROSA, A. S. A presença do intérprete de língua de sinais na mediação social entre surdos e ouvintes. In: SILVA, I.R.; KAUCHAKJE, S.; GESUELI, Z. M. Cidadania, surdez e linguagem. São Paulo: Editora Plexus, 2003.

Recebido em 06/ 06/ 2007

Reformulado em 22/ 11/ 2007

A provado em 25/ 02/ 2008 